\title{
Gute Stimmung in Brüssel
}

\section{Margarete Hofmann}

Vorsitzende der RG Brüssel im djb; Beamtin in der EU-Kommission, Referatsleiterin, Brüssel

Zehn Jahre Regionalgruppenbeirat - ein willkommener Anlass, das diesjährige RGB-Treffen in die europäische Hauptstadt Brüssel, in die EU-Vertretung des Landes NordrheinWestfalen zu verlegen. 26 Teilnehmerinnen aus den Regionalgruppen - mehr als je zuvor - sowie djb-Präsidentin Jutta Wagner, Vizepräsidentin Ramona Pisal und Geschäftsführerin Anke Gimbal waren der Einladung des RGB-Vorstands gefolgt. Die RG Brüssel hatte nicht nur schönstes Frühlingswetter mit viel Sonnenschein bestellt, sondern auch ein attraktives, belgisch angehauchtes Rahmenprogramm organisiert.

Eine individuelle Stadtführung (in deutscher Sprache), die ein Teil der Teilnehmerinnen wegen eines Streiks der belgischen Eisenbahnen am Freitag leider verpasste, führte in die Geschichte, Architektur und Kultur Brüssels ein. Eine Führung durch das 2009 eröffnete Magritte-Museum am Sonntag machte sehr anschaulich mit Leben und Werk des bekanntesten belgischen Malers der Moderne vertraut. Eine Entdeckungsreise in die surreale Phantasie von René Magritte.

Da Belgien für gutes und reichliches Essen bekannt ist, durften gastronomische Highlights im Programm natürlich nicht fehlen. Fast alle Teilnehmerinnen zog es zum BegrüBungsabend in die stimmungsvolle Weinbar „Ars Vinorum“. Das Samstagabend-Dinner fand im schönen Jugendstil-Restaurant „Les Brigittines“ statt. Der Qualität der Speisen stand die Qualität des Service in nichts nach, so zuvorkommende Kellner haben die djb-Frauen wohl schon lange nicht mehr erlebt.

Auch die inhaltliche Arbeit kam natürlich nicht zu kurz. Dr. Marianne Klingbeil, seit Kurzem Stellvertretende Generalsekretärin der Europäischen Kommission und damit höchstrangige deutsche Beamtin der EU-Kommission, hielt den Eröffnungsvortrag zum Thema „Europäische Gesetzgebung und bessere Rechtsetzung: Passt das zusammen?“, dem sich eine rege Diskussion anschloss.

\section{Neue Vorstandsmitglieder des RGB}

\section{Andrea Kirberger}

Vorsitzende des Regionalgruppenbeirates

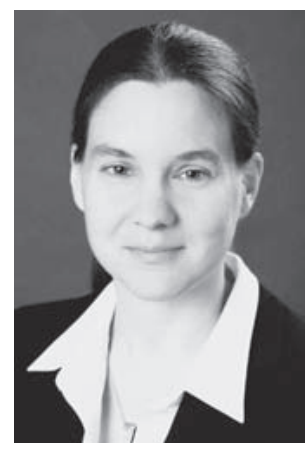

Ich wurde 1977 in Marburg an der Lahn geboren, bin jedoch seit 1979 in Siegen aufgewachsen. Nach dem Abitur im Jahr 1995 habe ich zunächst zwei Jahre in Konstanz Jura studiert, bevor ich 1997 an die rechtswissenschaftliche Fakultät der TU Dresden gewechselt bin. In Dresden habe ich im Jahr 2000 das 1. Staatsexamen abgelegt und daran anschließend das Referendariat beim OLG Dresden begonnen. Parallel zum Referendariat war ich einige Zeit als wissenschaftliche Hilfskraft an der TU Dresden beschäftigt.

Nach dem 2. Staatsexamen Ende 2002 wurde ich im Februar 2003 als Rechtsanwältin zugelassen und bin seitdem in der überörtlichen Anwaltssozietät Kirberger \& Partner GbR mit Standorten in Siegen und Dresden im Büro in Dresden als Rechtsanwältin tätig. Aufgrund des in der Kanzlei bereits seit Langem bestehenden fachlichen Schwerpunktes im Bau- und Architektenrecht habe ich mich ebenfalls sehr bald intensiv mit diesem Rechtsgebiet befasst und die Faszination des Baurechts kennengelernt. Seit Juli 2009 bin ich Fachanwältin für Bau- und Architektenrecht.

Im Juli 2008 habe ich mich entschieden, Mitglied im djb zu werden. Seit November 2009 bin ich als Schatzmeisterin im
Vorstand der Regionalgruppe Dresden und konnte in den Jahren 2010 und 2011 als Delegierte an den Sitzungen des Regionalgruppenbeirates teilnehmen. Im April 2011 bin ich in den Vorstand des Regionalgruppenbeirates gewählt worden.

\section{Daniela Leukert-Fischer \\ Vorsitzende des Regionalgruppenbeirates}

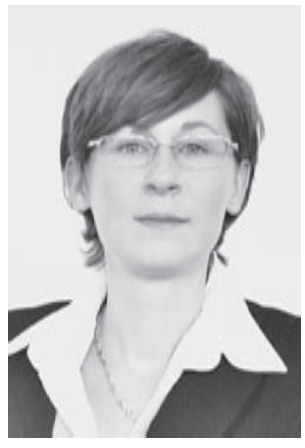

Geboren 1975 in Wernigerode/Harz, verheiratet, ein Sohn.

Studium der Rechtswissenschaft in Heidelberg und seit dem Referendariat Mitglied des djb.

Seit 2004 Rechtsanwältin mit dem Schwerpunkt im Wirtschafts- und Arbeitsrecht sowie im gewerblichen Rechtsschutz insbesondere Markenrecht.

Lehraufträge im Arbeitsrecht an der Frankfurt School of Finance \& Management und in den Bereichen Handels- und Gesellschaftsrecht, EDV-Recht und Arbeitsrecht an der Dualen Hochschule Baden-Württemberg/ Mannheim.

Mitglied der Regionalgruppe Karlsruhe und dort seit 2005 Vorstandsmitglied, u.a. Vorsitzende bis 2011.

Seit 2005 Mitglied im Regionalgruppenbeirat.

2011 Wahl in den Vorstand des Regionalgruppenbeirats. 